\title{
Joule per Kelvin
}

National Cancer Institute

\section{Source}

National Cancer Institute. Joule per Kelvin. NCI Thesaurus. Code C70447.

A SI unit of entropy used also as a unit of heat capacity. 